\title{
Survival of molar teeth after resective periodontal therapy - A retrospective study
}

\author{
Ka Leung Lee, Esmonde F. Corbet, W. Keung Leung* \\ Faculty of Dentistry, The University of Hong Kong, Hong Kong SAR, China
}

Running title: resective therapy - retrospective outcomes

Key words: furcation defects; molars; periodontal splints; periodontitis; proportional hazards models; tooth loss; treatment outcome

\section{*Corresponding author:}

W. K. Leung, Room 1B25, 34 Hospital Road, Prince Philip Dental Hospital, Faculty of Dentistry, The University of Hong Kong, Hong Kong SAR, China. Telephone: +852-2859-0417; Fax: +852-2858-2532; E-mail: ewkleung@hkucc.hku.hk

Date of re-submission: May 7, 2012

\section{Conflict of interest and source of funding statement}

The authors declare that there are no conflicts of interest in this study. The work described in this paper was partially supported by a grant from the Research Grants Council of the Hong Kong Special Administrative Region, China (772110M). 
Lee KL, Corbet EF, Leung WK. Survival of molar teeth after resective periodontal therapy - A retrospective study. J Clin Periodontol

\begin{abstract}
Aim: To study outcomes of molar teeth after resective therapy performed with the intention to prolong the lifespan of teeth having one or more unsaveable roots, and without which tooth extraction would be the only other treatment option.

Material and Methods: Clinical records of 149 subjects who had undergone resective therapy were retrieved. Demography and dental history were recorded, and a recall examination was undertaken. Cox regression models were performed.

Results: Of the 149 resective therapies, 132 (88.6\%) were performed for periodontal reasons. $89(59.7 \%)$ teeth subjected to resective therapies had been extracted by the time of recall a mean of 10 years post-resection. The median survival period was 74 months. Factors significantly associated with shorter survival duration of teeth subjected to resective therapy were: age at resective therapy; preoperative radiographic bone height of the remaining $\operatorname{root}(\mathrm{s})<50 \%$; pre-treatment mobility II or above; and not being splinted to neighbouring teeth nor incorporated as a bridge abutment.
\end{abstract}

Conclusions: There was increased risk of tooth loss with older patient age at resection, grade II mobility or above, and reduced preoperative radiographic bone heights around roots to remain. Splinting of a resected tooth to neighbouring teeth appeared to confer a protective effect towards its survival. 


\section{Clinical relevance}

Scientific rationale for the study: Furcation involvements commonly occur in multi-rooted teeth affected by periodontitis. Resective periodontal therapies provide clinicians with a possible therapeutic strategy in managing such affected teeth, and may often be applied as a 'last resort' to salvage a tooth, as in this study. Quantitative data on prognosis prediction for resective therapies as a 'last resort' form of therapy are lacking.

Principal findings: Older age at time of resection, pre-treatment tooth mobility II or above, pre-treatment radiographic bone height $<50 \%$ on $\operatorname{root}(\mathrm{s})$ to remain were all associated with reduced survival of resected molars, while periodontal splinting conferred protection against tooth loss.

Practical implication: The risk indicators identified may assist clinicians' decision-making processes and facilitate appropriate patient management when resective periodontal therapy is applied as a 'last resort' for furcation-involved molars. 
Molars affected by periodontal disease consequently developing furcation involvement usually respond less favourably to treatment compared with single-rooted teeth or molar teeth without furcation involvement (Nordland et al. 1987; Loos et al. 1989; Wang et al. 1994). Such furcation involved molars are at greater risk of loss following non-surgical periodontal therapy (Ekuni et al. 2009), an outcome possibly related to anatomical features, such as root concavities (Al-Shammari et al. 2001), cervical enamel projections (Chiu et al. 1991; Hou et al. 1994), and limited furcation entrance widths for access (Bower 1979). These can certainly impact upon the treatment of furcation involved molars in Asian populations (Hou \& Tsai 1987 \& 1997a; Zee et al. 1991).

Various therapeutic approaches had been suggested as definitive treatment for different degrees of furcation involvement (Carnevale et al. 2008, Walter et al. 2011). The effect of periodontal therapy on the survival of multi-rooted teeth with furcation involvement has been systematically reviewed (Huynh-Ba et al. 2009), and this review concluded that good long-term survival rates could be achieved. For furcations with advanced degree of involvement, resective therapy, such as root resection/amputation or hemisection, is a relatively common treatment. There has been a great variation reported for the survival data of teeth after resective treatment (Bergenholz 1972; Hamp et al. 1975; Klavan 1975; Langer et al. 1981; Erpenstein 1983; Buhler 1988; Basten et al. 1996; Blomlof et al. 1997; Carnevale et al. 1998; Dannewitz et al. 2006). The survival rates reported have ranged from less than $10 \%$ to up to $90 \%$ in various studies after varying periods of observation. The case selection, different resective procedures, quality of the endodontic therapy, the incorporation or not of the resected tooth in a fixed dental prosthesis, the type of restoration provided after resective treatment, and the caries susceptibility of the 
studied patients have all varied among the studies reported. It seems caution has to be applied in the comparison of the results from these studies. The systematic review concluded that vertical root fractures and endodontic failures were the most frequent complications following resective procedures (Huynh-Ba et al. 2009).

Amputation of roots of teeth was originally introduced as "radical and heroic" (Farrar 1884) and resective therapy is still often used as a 'last resort', as in the current study population. In the current study, resective therapy was performed simply to prolong the lifespan for the tooth if the tooth involved was not a second molar, if the position of the furcation was not situated far apically on the tooth, and if there was anticipated accessibility for homecare following resection (Hamp et al. 1975). Additional factors to be considered in evaluating respective treatment outcomes are the remaining periodontal support, occlusal antagonism, strategic value, patient's age and health conditions (Carnevale et al. 2008). This "last resort" treatment approach is actually favoured by Chinese patients who in general prefer tooth preservation over extraction (Razak et al. 1990). The aim of this study was to investigate retrospectively if various factors, including patients' demographic, oral health behaviour, supportive care, dental, periodontal and occlusal factors, may be associated with survival of root resected molar teeth in patients treated according to this approach.

\section{Material and Methods}

\section{Subjects}

Patients whose clinical files indicated that they had undergone root resection/amputation or hemisection therapy in the dental teaching hospital on or 
before December 31, 2006, which yielded at least one year post-resective therapy history, were included. To be included in this study the patient record must have shown that non-surgical mechanical therapy had been carried out before the resective therapy. Also, the record must have revealed that the resective surgery was carried out by either a teaching staff member of the Periodontology Clinic, or by a periodontology trainee under the supervision of a staff member. In brief, non-surgical mechanical periodontal therapy was performed on all Periodontology Clinic subjects, under local anesthesia when applicable. These cases were reviewed after a period of three-to-six months, typically, followed by a second round of non-surgical therapy, if needed. Patients were then carefully re-evaluated for residual pockets and determination of individual tooth prognosis. If molars with furcation involvement showed unfavorable or doubtful prognosis a discussion with the patient for consideration of extraction or retention of the tooth was conducted. For subjects favoring the latter treatment option, standard access flaps should be raised after endodontic treatment and proper direct coronal restoration of the tooth involved (Fig. 1) or a clear plan that endodontic treatment would be carried out shortly after the surgery. Upon exposing the involved root and furcation, root separation, extraction of the resected portion, root surface debridement of remaining roots, bevelling and/or smoothing to minimize plaque retention and enable homecare, all would be routinely performed. In keeping with the prime aim of prolonging the lifespan of the tooth, the resected tooth would not regularly have been prepared for extra-coronal restoration nor was ostectomy performed. Along the same lines, maxillary molars with residual furcation involvement would not receive root separation, rather the patient would be informed and instructed how to clean the furcation during homecare procedures. A small proportion of the included case were referrals from within the 
hospital or from private practise regarding respective therapy due to other reasons such as failed endodontic treatment or root fracture. In brief, these subjects would receive non-surgical periodontal therapy or endodontic treatment as needed, and then resective therapy as described above.

For treated periodontal patients, structured supportive periodontal care (SPC) was normally provided by the Periodontology Clinic, in which the patients would be followed up at least twice a year for careful oral hygiene instructions and professional periodontal debridement provided by academic staff and/or trainee periodontists assisted by dental hygienists. The local water is fluoridated (Wong et al. 2006) hence the Periodontology Clinic does not routinely deliver professionally applied fluoride, unless a clear indication for remineralization of early lesion is apparent. Patients under SPC would be discharged if they declined further treatment, which to some extent happened when their responsible clinicians left the hospital, typically on completion of their education and/or training. Other patients who had received resective treatment were referred from the private sector or other divisions of the hospital, and these patients were instructed to receive supportive periodontal care from their referral sources.

The resected tooth needed to have been endodontically treated before, or within one month after, the resective therapy. Both pre-resective therapy and post-resective radiographs needed to be available in the patients' records. Non-Chinese patients and patients with medical conditions suggesting a need for antibiotic prophylaxis were excluded. For subjects who had more than one tooth with root resection, chronologically the first one in the record fulfilling the recruitment criteria was selected. A total of 379 patients were recorded as having had resective procedures performed. Forty two patients were excluded because required radiographs were not 
available. One hundred patients could not be contacted, and 88 patients declined to participate. One hundred forty nine patients (62.9\%) agreed to participate. Data collection, by one designated examiner (KLL), was finished by December 2007. All of the patients who had declined to attend were subsequently surveyed through telephone calls regarding the survival of their resected tooth.

A two-part questionnaire collected data on educational level, family income, occupation, smoking, diet habit - particularly hard food consumption, oral hygiene habits, denture wearing, general health status, compliance with dental recalls (cross-checked with hospital dental records, if available and a history of private supportive periodontal care would be confirmed by contacting the patients' private practitioners), and subjective tooth mobility (Fleszar et al. 1980) of the resected tooth. The time and reasons for any loss of resected teeth and self-reported survival duration were recorded. The tooth loss data, whenever possible (in subjects who received SPC in the Periodontology Clinic, or check-ups in other clinics of the dental hospital, or whose tooth of concern was extracted in the teaching hospital), was cross checked against the hospital records. For teeth of concern extracted elsewhere, the self-reported information was considered accurate and was used in this study.

\section{Pre-resective therapy clinical records}

The following pre-root resection clinical records were retrieved from each patient's file:

Pre-treatment tooth mobility: recorded according to Miller's classification (1938).

Pre-treatment paralleling periapical radiographs were used for assessment of the following aspects: Root trunk length: relative distance from radiographic furcation to 
cemento-enamel junction (CEJ) (Hou et al. 2005). Root divergence angle: the angle between the coronal intercepts of long axes of the resected root and the remaining $\operatorname{root}(\mathrm{s})$. Greater than or equal to 15 degrees was considered as 'divergent'. In upper molars measurement was only possible between mesio-buccal and disto-buccal roots. Remaining bone level: subcategorised into $75 \%, 50-74 \%$ and $<50 \%$ presented as the mean between mesial and distal aspects of the remaining root(s). When more than one root remained, radiographic bone levels at mesial and distal aspects of both or all roots were averaged. Crown-root ratio: All values for mesial and distal aspects of all roots were averaged to yield the final data per tooth. For the parameters root trunk length, remaining bone level and crown-root ratio, the measurements were recorded by a Schei ruler after radiographic identification of the cusp tip of concern, the CEJ, and the appropriate root apex. For teeth which had received extra-coronal restorations, the crown margin was use in lieu of the CEJ. If there was extensive direct restoration having proximal margins beyond the CEJ, the restoration's gingival margin would be used as the reference point. For any case with altered reference points, restorations altering cusp tips, covering the CEJs at proximal restoration margin, at any stage when data collection was needed, data was be excluded. Endodontic treatment quality: Intra-radicularly - dichotomised into 'good' or 'not good' according to the Consensus Report of the European Society of Endodontology (2006) based on quality of root filling and/or over-preparation. Pre-treatment radiographic apical lesion size: categorised arbitrarily according to radiographic widest diameter of lesion size: $\leq 2.0 \mathrm{~mm} ; 2.1-4.0 \mathrm{~mm} ; \geq 4.1 \mathrm{~mm}$. Clinical decision for $\operatorname{root}(\mathrm{s})$ removal was not recorded nor considered in the current study. Rather, only the exact number and location of the root(s) resected and hence the root(s) being retained were considered. 


\section{Post-resective therapy clinical records}

The following early post-root resection clinical records were retrieved from each patient's file:

Quality of root resection: Any radiographic ledges, furcation lips, residual root fragments or concavities created during the resective procedure were considered as unsatisfactory resective treatment (Newell 1991).Caries: if there was any sign of clinical (reported in record) and/or radiographic caries found on any root surface. Restorative status after resective therapy: simple direct (bonded amalgam or posterior composite) restoration, or coronal coverage restorations, bridge abutment, or splinted to neighbouring tooth/teeth. Presence of post and core: yes: either cast or prefabricated; or no. Occlusal factors: The antagonistic units were categorised into: i) Fixed units- tooth or tooth or implant borne crown or bridge unit; ii) Removable denture units; or iii) No antagonist. Number of occlusal pairs for resected tooth: premolar size antagonists were considered as a single unit pair; molar-sized occlusion was counted as a double-unit (Kayser 1981).

\section{Clinical examinations}

These examinations were performed by one examiner (KLL). Plaque - presence or absence, bleeding on probing (BOP), recession (REC), probing pocket depth (PPD) and probing attachment level (PAL) were measured at six sites (mesio-buccal, mid-buccal, disto-buccal, mesio-palatal, mid-palatal and disto-palatal) on each tooth except third molars and retained roots. PCP-UNC 15 probe (Hu-Friedy, Chicago, IL) was used. The measurement of REC, PPD, and PAL was performed according to 
a reported protocol (Pilgram et al. 2000), and tooth sites associated with tooth impaction or having the CEJ indeterminable were excluded.

A paralleling periapical radiograph was taken if the resected tooth was still present. Similar radiographic measurements as for the pre- and earlier post-resective therapy radiographs were recorded. In addition, any increase in the size of any apical lesion, change in radiographic density of root canal fillings, and widening of periodontal ligament space was recorded.

\section{Data analysis}

Standard descriptive statistical analysis was conducted to synthesize the raw data. The association between the dependent variable, the survival of the resected tooth at recall, to the various pre- or earlier post-treatment independent variables was assessed. The independent variables were: age at the time of resective therapy, gender, educational level, smoking, dietary habits, denture wearing, compliance with dental check-up, oral hygiene practice, pre-treatment tooth mobility, root morphology, type of remaining $\operatorname{root}(\mathrm{s})$, quality of resective therapy, endodontic treatment quality, pre-treatment periapical lesion size, radiographic bone level on the remaining root(s), radiographic crown-root ratio, the restorative status after root resection, and any splinting of resected tooth to neighbouring teeth. Similarly, univariate analysis between period of resected tooth survival and various independent variables was performed using Kaplan-Meier analysis/log-rank test to detect which decisive variables would be significantly associated with period of resected tooth survival without consideration of confounding variables. In brief the independent variable were: age at root resection and at recall, gender, smoking, regular dental check-up, tooth type, pre-resection tooth mobility, the following parameters at recall - P1\%, BOP\%, full mouth mean PPD, 
missing teeth, denture wearing, and any parameters found significantly associated with missing resected tooth at recall. Univariate analysis of association between period of resected tooth survival and various independent variables was calculated according to the Kaplan-Meier product limit estimation. Time zero was defined as the date when the resective treatment was carried out. The surviving resected teeth data and self-reported survival data regarding the lost resected teeth were recorded on the recall data collection visit. The calculated survival curve was the 'maximum likelihood' estimate of the true survival curve. Multivariate Cox regression model was then constructed, based on the above predetermined independent variables and those appearing to be significantly associated with i) survival of resected teeth at recall, and ii) period of survival of resected tooth from the Kaplan-Meier analysis. Significance level of 0.05 was adopted. All data were analysed using the Statistical Package for Social Science, version 16.0 (SPSS, Chicago, IL, USA).

\section{Results}

The majority $(88.6 \%)$ of patients receiving resective therapy in the Periodontology Clinic had suffered from severe attachment loss such that the resective treatment was the only viable option to prolong the lifespan of the involved tooth. Hence the indication for root resection had not changed during the period of patient treatment under consideration which was a median of 9.0 and a mean of $9.0 \pm 5.7$ years.

Only seventeen (11.4\%) of the 149 patients were non-periodontitis cases. Out of the 132 periodontal patients, $87(65.9 \%)$ of them had received at least biannual SPC, $72(54.5 \%)$ at the Periodontology Clinic and $15(11.4 \%)$ from private dental practitioners. The others $(\mathrm{n}=45$ periodontitis patients, and 17 non-periodontitis 
patients), despite having been recommended, as is routine, to seek regular SPC from private dentists, had in reality attended less than twice per year.

Among the teeth of interest, 70 had Degree I furcation(s), 79 had Degree II or III furcation(s) involvement recorded, however many furcation involvements recorded as Degree I on the basis of the clinical examination were found on surgical exploration to be more severely involved in terms of furcation involvement or in terms of advanced attachment loss localised to one root. Furcation status of other molars was not noted for this study because it was not always possible to compare every furcation entry in the clinical notes against a corresponding intra-oral radiograph.

Hemisection had been carried out in 23 teeth (15.4\% patients), while root amputation/resection had been performed for the remaining 126 teeth. Of the teeth which had undergone resective therapy, 76 (51.0\%) were upper first molars, 13 (8.7\%) were upper second molars, 43 (28.9\%) were lower first molars and 17 (11.4\%) were lower second molars. For upper first and second molars, resection of mesiobuccal, distobuccal, both buccal, or palatal root(s) accounted for 15 (10.1\%), 21 (14.1\%), 7 (4.7\%) and $46(30.9 \%)$ cases, respectively. For lower molars, resection of mesial or distal root both individually accounted for 30 (20.1\%) cases. Furcation involvement remained present between the standing roots of 39 resected upper molars. Forty eight $(32.2 \%)$ of the resected teeth received extra-coronal restoration.

Mean age of patients when they had undergone resective therapy was 47.3 years (range 19-83 years) and the mean age at recall was $57.3 \pm 10.6$ years. Demographic data and habits of participants are summarized in Table 1. Overall tobacco exposure of the 34 smokers and ex-smokers was $19.5 \pm 14.5$ pack-years. The observation period of resected teeth ranged from 1 to 24 years, categorized as: 1-5 years (31.5\%); 6-10 years $(28.9 \%)$; $11-15$ years $(24.8 \%)$; and $\geq 16$ years $(14.8 \%)$. 
The mean $( \pm \mathrm{SD})$ and the median survival of resected teeth were $73( \pm 58.9)$ and 74 months, respectively. Eighty nine (59.7\%) of the resected teeth had been lost prior to re-evaluation. Of these, clear indications for $73(82.0 \%)$ tooth extractions could be determined, while for the rest $(n=16)$ the reasons for extraction were self-reported. The total reported reasons for loss were: periodontal causes $(n=66,74.2 \%)$, fractured root $(n=14,15.7 \%)$, endodontic problems or root resorption $(n=6,6.7 \%)$, and caries $(\mathrm{n}=3,3.4 \%) . \quad$ In total 931 first and second molars, including the subject teeth, were present in the 149 subjects at baseline (Table 2). Those reporting regular SPC had lost a mean of 0.6 first or second molars, while those reporting non-adherence to regular recalls lost a mean of 1.0 first or second molars. Tobacco exposure was not associated with survival of resected teeth at recall.

The reported survival period of the 89 lost resected teeth was between: 0-3 years for $40(44.9 \%)$; $4-6$ years for $24(27.0 \%)$; 7-9 years for 7 (7.9\%); 10-12 years for 11 (12.4\%); and >12 years for $7(7.9 \%)$. For the 40 teeth lost in the first 3 years, 30 teeth (75\%) were reported lost due to periodontal reasons or excessive mobility, 5 (12.5\%) due to root fracture and the remaining $5(12.5 \%)$ due to endodontic problems. Eighteen (45\%) out of these 40 teeth were assessed as having bone level $<50 \%$ on remaining roots from the post-resective radiograph.

For the 88 patients who were contacted by phone or mail but declined to participate in the clinical study, all were subsequently contacted by telephone. 41 (response rate $46.6 \%$ ) agreed to answer questions about the status of their resected tooth. Their mean age at resection was $46.1 \pm 10.0$ years and at telephone contact was $60.7 \pm 9.3$ years. Twenty-four $(58.5 \%)$ resected teeth were reported as surviving over the mean period of 14.6 years. 
Background characteristics of all subjects are as shown in Table 1. For those subjects self-reporting or verified through hospital records as having regular dental check-ups professional fluoride application was not noted. Subjects who reported using interdental brushes daily were found to have lower P1\% and $\mathrm{BOP} \%(\mathrm{p} \leq 0.021)$. Preliminary univariate analysis indicated that patients with resected tooth present at recall: i) were younger than those who had lost the resected tooth, and ii) reported regular dental check-ups. No significant association was detectable between the subjects' gender, systemic disease status, economic factors, educational level, smoking, dietary plus oral hygiene habits and the survival of the resected tooth (Table $1)$.

The tooth type of the resected tooth, pre-treatment tooth mobility, root morphology, endodontic treatment quality did not significantly correlate with survival at recall. There was no significant correlation of any pre-treatment periapical radiographic lesion size with resected tooth survival. The location of remaining $\operatorname{root}(\mathrm{s})$, antagonistic occluding units, quality of root resection, post-resective treatment did not significantly associate with resected tooth survival at recall. Pre-resection tooth support, post-resection restoration status, including post and core usage, appeared to associate with resected tooth survival at recall. Not wearing denture(s), having fewer decayed (DT) or filled teeth (FT), and less full-mouth mean recession at re-examination appeared to be associated with survival of resected tooth at recall (Table 3).

The median (50\%) estimated survival of the resected molars was 74 months. According to the Kaplan-Meier plot (data not shown), one-half of the resected teeth were lost after six years. The estimated 10-year post-resection survival was $39 \%$. 
The variables found to have significant correlation (without controlling for the confounding variables) with resected tooth survival are summarised in Table 4. Reduced bone height $\square 50 \%$, and mobility $\geq \mathrm{M}$ II were associated with reduced survival while use as a bridge abutment or being splinted was associated with increased survival. Based on the above, a multivariate Cox proportional hazards regression model was developed (Table 5). Only teeth with $>75 \%$ bone level had a significantly longer survival period $(\mathrm{p}<0.001)$ compared to those with $<50 \%$ bone level in the adjusted Cox regression model. There was more than four times increased risk in tooth loss of for teeth with $<50 \%$ bone, compared to those with $>75 \%$ bone. Teeth presenting with MII or greater pre-treatment mobility were at a three-fold higher risk of tooth loss than non-mobile teeth. Significant decrease, by $74 \%$, was found in the risk of tooth loss for splinted resected teeth compared to those teeth restored with unsplinted restorations. Patients' older age at time of resective treatment was found to be significantly associated with poorer survival. Harrell's C of 0.6924 indicates that one can correctly order survival times for pairs of patients approximately $70 \%$ of the time on the basis of the variables in the model (Harrell et al. 1996).

\section{Discussion}

The results from the current study indicate that for molar teeth with hopeless root(s) mostly with extensive periodontal damage, several factors appear to positively or negatively affect the tooth survival after resective periodontal therapy. These are: pre-treatment radiographic bone level on the root(s) to remain, pre-treatment mobility, coronal protection and splinting. Such information may assist clinicians in treatment 
planning resective therapy as well as in designing post-operative management strategies in an attempt to prolong the life of a tooth treated by a resective approach as a last resort intervention for a furcation involved tooth, or a multi-rooted tooth with an endodontic mishap or root fracture affecting only one root.

Similar to an earlier local report (Leung et al. 2006), the majority (53.1\%) of the total first or second molar teeth lost over the post-treatment period in these patients were from subjects $(42.1 \%)$ not complying with SPC advice. Due to the limitations of the retrospective study design, it was not possible to retrieve reliable further data to compare exactly first and second molar tooth loss according to SPC compliance, smoking, treatment type received (non-surgical and/or surgical) for resected versus non-resected molar survival in the current patient cohort.

More severely involved teeth may not be retained or treated, with $44 \%$ of all teeth with furcation involvement being extracted as part of initial treatment in one study (Hamp et al. 1975). Resective therapy may be performed as a definitive treatment approach (Carnevale et al. 1991; Carnevale et al. 1998), or it may be performed as a last resort type of therapy to extend the functional survival of teeth having one root with advanced attachment loss, as in this study. It is difficult to compare different study outcomes unless the treatment approaches adopted and treatment goals set are reported in sufficient detail. The clinical decision for $\operatorname{root}(\mathrm{s})$ removal before, based upon pre-treatment clinical examination and plain radiography, or during the root resective surgical procedure, based on direct appreciation of the clinical defect/problem (Walter et al. 2009,) was not studied.

By the nature of this retrospective study, some of the patients who had received resective therapy could not be recalled because their contacts were no longer valid or because they had passed away. Some of the patient information retrieved from the 
patient clinical files did not satisfy the inclusion criteria. A fair proportion of those who had received resective therapy, refused to participate in this project as it involved a recall visit to the dental teaching hospital. All of those who refused to participate but who were willing to answer questions were interviewed by telephone. They were older than those who participated this project and reported a longer resected tooth survival period. Thus non-attendance by potential patients may have suggested less favourable survival than actually experienced. The number of patients successfully recalled, 149, is comparable to a similar Hong Kong study on treatment outcomes (Leung et al. 2006).

A range of clinical factors may influence treatment decisions for periodontally involved molars (Svardstrom \& Wennström 2000), as may dentists' treatment preferences (Zitzmann et al. 2011). In the present study, $89 \%$ of the patients receiving resective therapy had suffered from severe attachment loss not affecting all roots to a similar extent. The alveolar bone support on the remaining root(s) was not optimal in every case. Around half of the resected teeth in this study presented with pre-treatment $<75 \%$ radiographic bone support, with $20 \%$ having only $<50 \%$. The median survival of a resected tooth with pre-treatment $<50 \%$ remaining radiographic bone support was only 2.1 years (data not shown). Reduced bone height might constitute a possible reason why 40 of the 89 extracted resected teeth were lost in the first 3 years. The attempt to prolong the life of some teeth with questionable prognosis having minimal bone height on roots to remain by respective therapy as a 'last ditch' form of therapy may explain the relatively high failure rate of this treatment approach in this study. Another study of root resection therapy in an Asian population also concluded that the roots to remain should have sufficient bone support (Park et al. 2009). 
Complicating respective therapeutic approaches for lower first molars in the Chinese is a high prevalence, up to $21 \%$, of an extra disto-lingual root (Walker \& Quackenbush 1985; Huang et al. 2007; Tu et al. 2007). This study however did not show any significant association between any particular type of resected tooth and post-resection survival, which is in agreement with an earlier study (Blomlof et al. 1997).

This study found that there was no significant association between resected tooth survival and reported consumption of hard foods, including the chewing of bones. Recommendations that remaining roots on resected molars be subjected to only the lightest loads possible (Langer 1996) cannot in practice work in a population in which masticatory activities such as the chewing of bones is commonplace.

In the present study, periodontal causes/excessive mobility was the major reason for failure, accounting for $75 \%$ of the resected tooth loss. Fractured root was the second commonest mode of failure, accounting for $15 \%$ of resected teeth lost, not dissimilar to the proportion of resected teeth lost due to fracture (18.6\%) in another Asian study (Park et al. 2009).

The teeth which were most commonly resected, as a last resort therapy, in this study in descending order were: upper first molars, lower first molars, lower second molars and upper second molars. A higher prevalence of furcation involved molars has been reported in the maxilla (Hirschfeld \& Wasserman 1978; McFall 1982; Svardstrom \& Wennström 1996) possibly due to differences in the number of furcation entrances or differences in accessibility of furcation entrances for plaque control.

Only one-fifth of patients in this study had undergone resective therapy on second molars. A higher prevalence of unfavourable anatomical features in upper 
second molars in the Chinese race, long root trunks and fused roots (Hou \& Tsai 1997b), often preclude successful resective therapy. It has been reported that extraction was indicated two-times more commonly for periodontally involved second molars than for first molars (Müller et al. 1995).

Root resected teeth are often subsequently subjected to various types of restorative treatment, which may further complicate the interpretation of results of the respective therapeutic approach itself. Some studies (Carnevale et al. 1991; Carnevale et al. 1998) showed a remarkably high survival rate (93\%) over 3-11 years, but $62 \%$ of the treated teeth were treated with root separation and not root resection, while the prosthetic plan for $87 \%$ of the treated teeth was splinting through incorporation as abutments for fixed dental prostheses. The longevity of endodontically-treated, which teeth treated by resective therapies invariably become, has been the focus of several recent studies. Endodontically-treated molars with maximum coronal tooth structure remaining after endodontic access can be restored without crown placements, yielding fair long-term survival (median $>7.9$ years), irrespective of type of direct restoration material (Nagasiri \& Chitmongkolsuk 2005). However another retrospective study showed that endodontically-treated teeth which were not crowned were at a 6-fold greater risk to be lost than a crowned root treated tooth (Aquilino \& Caplan 2002) while crowned endodontically-treated teeth have been shown to have similar survival rates as crowned teeth with vital pulps (Valderhaug et al. 1997). However his study showed that splinting of resected teeth offered protection.

Fifty eight percent of patients in this study reported biannual dental check-ups, not a common reported practice among the general population of Hong Kong (Oral Health Survey 2001) or in treated periodontitis patients in Hong Kong (Leung et al. 2006). However on the basis of the multivariate analysis, regular dental recalls in the 
Periodontology Clinic and/or at patients' own general dentists did not seem to be associated with better post-resection molar survival (Table 4). Considering the potential differences between the quality of SPC provided by the Periodontology Clinic compared to the quality of the supportive care delivered in general dental practices, and the difficulties for those attending private dentists to remember exactly what services had been offered and availed of, no attempt was made to analyse the effect of quality of preventive treatment received during dental check-ups on resected molar survival. Nevertheless, regularity of maintenance has been shown to be significant in terms of preservation of teeth with furcation lesions (Rosling et al. 1976; Nyman et al. 1977; Checchi et al. 2002; Pretzl et al. 2008) and should thus be routinely recommended.

\section{Conclusion}

The present study investigated retrospectively factors which may be associated with the clinical survival of resected molar teeth in a teaching hospital-based periodontal patient pool. Most of the resective treatment was carried out for teeth with one, or more, hopeless root(s), mostly with extensive periodontal damage, in an attempt to prolong the life of the teeth. Several factors were demonstrated to affect molar tooth survival after resective periodontal therapy: younger age at resection and splinting of resected teeth to neighbouring teeth conferred significant positive effects, while teeth with reduced pre-treatment radiographic bone levels on the root(s) to remain and teeth with pre-resective treatment mobility of Degree II or above were at risk of earlier loss. Findings from the present study could therefore provide clinicians with guidance in managing a periodontally involved molar with advanced attachment loss, for which 
resective therapy may be considered so as to avoid tooth extraction and extend the functional longevity of the tooth.

\section{Acknowledgment}

The work described in this paper was partially supported by a grant from the Research Grants Council of the Hong Kong Special Administrative Region, China (HKU 772110M). We acknowledge Mr. K. W. Shadow Yeung's assistance in the data analysis. 


\section{Reference}

Al-Shammari, K. F., Kazor, C. E. \& Wang, H. L. (2001) Molar root anatomy and management of furcation defects. Journal of Clinical Periodontology 28, 730-740.

Aquilino, S. A. \& Caplan, D. J. (2002) Relationship between crown placement and the survival of endodontically treated teeth. Journal of Prosthetic Dentistry 87, 256-263.

Basten, C. H., Ammons, W. F., Jr. \& Persson, R. (1996). Long-term evaluation of root-resected molars: a retrospective study. International Journal of Periodontics and Restorative Dentistry16, 206-219.

Bergenholtz, A. (1972) Radectomy of multi-rooted teeth. Journal of American Dental Association 85, 870-875.

Blomlof, L., Jansson, L., Appelgren, R., Ehnevid, H. \& Lindskog, S. (1997) Prognosis and mortality of root-resected molars. International Journal of Periodontics and Restorative Dentistry 17, 190-201.

Bower, R.C. (1979) Furcation morphology relative to periodontal treatment. Furcation entrance architecture. Journal of Periodontology 50, 23-27.

Buhler, H. (1988) Evaluation of root-resected teeth. Results after 10 years. Journal of Periodontology 59, 805-810.

Carnevale, G., Di Febo, G., Tonelli, M. P., Marin, C. \& Fuzzi, M. (1991) A retrospective analysis of the periodontal-prosthetic treatment of molars with interradicular lesions. International Journal of Periodontics and Restorative Dentistry 11, 189-205. 
Carnevale, G., Pontoriero, R. \& Di Febo, G. (1998) Long-term effects of root-resective therapy in furcation-involved molars. A 10-year longitudinal study.Journal of Clinical Periodontology 25, 209-214.

Carnevale, G., Pontoriero, R. \& Lindhe, J. (2008) Treatment of furcation-involved teeth. In: Lang, N. P. \& Lindhe, J., editors, Clinical Periodontology and Implant Dentistry, 5th edition, Volume 2, 823-847, Oxford, Blackwell Munksgaard.

Checchi, L., Montevecchi, M., Gatto, M. R. A. \& Trombelli, L. (2002) Retrospective study of tooth loss in 92 treated periodontal patients. Journal of Clinical Periodontology 29, 651-656.

Chiu, B. M., Zee, K. Y., Corbet, E. F. \& Holmgren, C. J. (1991) Periodontal implications of furcation entrance dimensions in Chinese first permanent molars. Journal of Periodontology 62, 308-311.

Dannewitz, B., Krieger, J. K., Husing, J. \& Eickholz, P. (2006) Loss of molars in periodontally treated patients: a retrospective analysis five years or more after active periodontal treatment. Journal of Clinical Periodontology 33, 53-61.

Dental Service Head Office (2002) Oral Health Survey 2001: Common dental diseases and oral health related behaviour. Hong Kong SAR: Department of Health.

Ekuni, D., Yamamoto, T. \& Takeuchi, N. (2009) Retrospective study of teeth with a poor prognosis following non-surgical periodontal treatment. Journal of Clinical Periodontology 36, 343-348.

Erpenstein, H. (1983) A 3-year study of hemisectioned molars. Journal of Clinical Periodontology 10, 1-10. 
European Society of Endodontology (2006) Quality guidelines for endodontic treatment: consensus report of the European Society of Endodontology. International Endodontic Journal 39, 921-930.

Farrar, J. N. (1884) Radical and heroic treatment of alveolar abscess by amputation of roots of teeth. Dental Cosmos 26, 79.

Fleszar, T. J., Knowles, J. W., Morrison, E. C., Burgett, F. G., Nissle, R. R. \& Ramfjord, S. P. (1980) Tooth mobility and periodontal therapy. Journal of Clinical Periodontology7, 495-505.

Hamp, S.-E., Nyman, S. \& Lindhe, J. (1975) Periodontal treatment of multi rooted teeth. Results after 5 years. Journal of Clinical Periodontology 2, 126-135.

Harrell, F. E. Jr, Lee, K. L. \& Mark, D.B. (1996) Multivariable prognostic models: issues in developing models, evaluating assumptions and adequacy, and measuring and reducing errors. Statistics in Medicine 15, 361-387.

Hirschfeld, L. \& Wasserman, B. (1978) A long-term survey of tooth loss in 600 treated periodontal patients. Journal of Periodontology 49, 225-237.

Hou, G. L. \& Tsai, C. C. (1987) Relationship between periodontal furcation involvement and molar cervical enamel projections. Journal of Periodontology 58, 715-721.

Hou, G. L. \& Tsai, C. C. (1997a) Cervical enamel projection and intermediate bifurcational ridge correlated with molar furcation involvements. Journal of Periodontology 68, 687-693.

Hou, G. L. \& Tsai, C. C. (1997b) Types and dimensions of root trunk correlating with diagnosis of molar furcation involvements. Journal of Clinical Periodontology 24, 129-135. 
Hou, G. L., Chen, S. F., Wu, Y. M. \& Tsai, C. C. (1994) The topography of the furcation entrance in Chinese molars. Furcation entrance dimensions. Journal of Clinical Periodontology 21, 451-456.

Hou, G. L., Hung, C. C., Tsai, C. C. \& Weisgold, A. S. (2005) Topographic study of root trunk type on Chinese molars with Class III furcation involvements: molar type and furcation site. International Journal of Periodontics and Restorative Dentistry 25, 173-179.

Huang, R.-Y., Lin, C.-D., Lee, M.-S., Yeh, C.-L., Shen, E.-C., Chiang, C.-Y., Chiu, H.-C.\& Fu, E. (2007) Mandibular disto-lingual root: A consideration in periodontal therapy. Journal of Periodontology78, 1485-1490.

Huynh-Ba, G., Kuonen, P., Hofer, D., Schmid, J., Lang, N. P. \& Salvi, G. E. (2009) The effect of periodontal therapy on the survival rate and incidence of complications of multirooted teeth with furcation involvement after an observation period of at least 5 years: systematic review. Journal of Clinical Periodontology 36, 164-176.

Kayser, A. F. (1981) Shortened dental arches and oral function. Journal of Oral Rehabilitation 8, 457-462.

Klavan, B. (1975) Clinical observations following root amputation. Journal of Periodontology 46, 1-5.

Langer, B. (1996) Root resection revisited. International Journal of Periodontics \& Restorative Dentistry 16, 200-201.

Langer, B., Stein, S. D. \& Wagenberg, B. (1981) An evaluation of root resections - a 10-year study. Journal of Periodontology 52, 719-722. 
Leung, W. K., Ng, D. K., Jin, L. \& Corbet, E. F. (2006) Tooth loss in treated periodontitis patients responsible for their supportive care arrangements. Journal of Clinical Periodontology 33, 265-275.

Loos, B., Nylund, K., Claffey, N. \& Egelberg, J. (1989) Clinical effects of root debridement in molar and non-molar teeth. A 2-year follow-up. Journal of Clinical Periodontology 16, 498-504.

McFall, W. T., Jr. (1982) Tooth loss in 100 treated patients with periodontal disease. A long-term study. Journal of Periodontology 53, 539-549.

Miller, S. (editor) (1938) Textbook of Periodontia, 1st edition, Philadelphia: Blakiston.

Müller, H. P., Eger, T. \& Lange, D. E. (1995) Management of furcation-involved teeth. A retrospective analysis. Journal of Clinical Periodontology 22, 911-917.

Nagasiri, R. \& Chitmongkolsuk, S. (2005) Long-term survival of endodontically treated molars without crown coverage: A retrospective cohort study. Journal of Prosthetic Dentistry 93, 164-170.

Newell, D. H. (1991) The role of the prosthodontist in restoring root-resected molars: a study of 70 molar root resections. Journal of Prosthetic Dentistry65, 7-15.

Nordland, P., Garrett, S., Kiger, R., Vanooteghem, R., Hutchens, L. H. \& Egelberg, J. (1987) The effect of plaque control and root debridement in molar teeth. Journal of Clinical Periodontology 14, 231-236.

Nyman, S. R., Lindhe, J. \& Rosling, B. (1977) Periodontal surgery in plaque-infected dentitions. Journal of Clinical Periodontology 4, 240-249. 
Park, S. Y., Shin, S. Y., Yang, S. M. \& Kye, S. B. (2009) Factors influencing the outcome of root-resection therapy in molars: a 10-year retrospective study. Journal of Periodontology 80, 32-40.

Pilgram, T. K., Hildebolt, C. F., Yokoyama-Crothers, N., Dotson, M., Cohen, S. C., Hauser, J. F. \& Kardaris, E. (2000) Relationships between radiographic alveolar bone height and probing attachment level: data from healthy post-menopausal women. Journal of Clinical Periodontology 27, 341-346.

Pretzl, B., Kaltschmitt, J., Kim, T.-S., Reitmeir, P. \& Eickholz, P. (2008) Tooth loss after active periodontal therapy. 2: tooth-related factors. Journal of Clinical Periodontology 35, 175-182.

Razak, I. A., Jaafar, N., Jalalludin, R. L. \& Esa, R. (1990) Patient's preference for exodontia versus preservation in Malaysia. Community Dentistry and Oral Epidemiology 18, 131-132.

Rosling, B., Nyman, S. \&Lindhe, J. (1976) The effect of systematic plaque control on bone regeneration in infrabony pockets. Journal of Clinical Periodontology $\mathbf{3}$, $38-53$.

Svardstrom, G. \& Wennström, J. L. (1996) Prevalence of furcation involvements in patients referred for periodontal treatment. Journal of Clinical Periodontology 23, 1093-1099.

Svardstrom, G. \& Wennström, J. L. (2000) Periodontal treatment decisions for molars: an analysis of influencing factors and long-term outcome. Journal of Periodontology 71, 579-585.

Tu, M.-G., Tsai, C.-C., Jou, M.-J., Chen, W.-L., Chang, Y.-F., Chen, S.-Y. \& Cheng, H.-W. (2007) Prevalence of three-rooted mandibular first molars among Taiwanese individuals. Journal of Endodontics 33, 1163-1166. 
Valderhaug, J., Jokstad, A., Ambjornsen, E. \& Norheim, P. W. (1997) Assessment of the periapical and clinical status of crowned teeth over 25 years. Journal of Dentistry 25, 97-105.

Walker, R. T. \& Quackenbush, L. E. (1985) Three-rooted lower first permanent molars in Hong Kong Chinese. British Dental Journal 159, 298-299.

Walter, C., Kaner, D., Berndt, D. C., Weiger, R. \& Zitzmann N. U. (2009) Three-dimensional imaging as a ore-operative tool in decision making for furcation surgery. Journal of Clinical Periodontology 36, 250-257.

Walter, C., Weiger, R. \& Zitzmann N. U. (2011) Periodontal surgery in furcation-involved maxillary molars revisited - an introduction of guidelines for comprehensive treatment. Clinical Oral Investigations 15, 9-20.

Wang, H. L., Burgett, F. G., Shyr, Y. \& Ramfjord, S. (1994). The influence of molar furcation involvement and mobility on future clinical periodontal attachment loss. Journal of Periodontology 65, 25-29.

Wong, H. M., McGrath, C. P. J., Lo, E. C. M. \& King, N. M. (2006) Association between developmental defects of enamel and different concentrations of fluoride in the public water supply. Caries Research 40, 481-486.

Zee, K. Y., Chiu, M. L., Homlgren, C. J., Walker, R. T. \& Corbet, E. F. (1991) Cervical enamel projections in Chinese first permanent molars. Australian Dental Journal 36, 356-360.

Zitzmann, N. U., Scherrer, S. S., Weiger, R., Lang, N. P. \& Walter, C. (2011) Preferences of dental care providers in maintaining compromised teeth in relation to their professional status: implants instead of periodontally involved maxillary molars? Clinical Oral Implants Research 22, 143-150. 


\section{Legend}

Fig. 1.A case of a 41 year-old female with combined periodontal-endodontic lesion at lower left first molar (tooth 36) requiring distal root resection in lieu of extraction. a) radiographic presentation of lesion before and b) after root canal therapy; c) lingual and d) buccal views of lower left mandibular posterior region before root resection while shortly after non-surgical periodontal therapy and root treatment; e) resective surgery on 36 distal; f) radiographic presentation, g) lingual and h) buccal views of 36 at recall, i.e. 25 months post-resection and regular SPC. 
Table1. Background characteristics of study participants

\begin{tabular}{|c|c|c|c|c|c|c|}
\hline \multirow[b]{2}{*}{ Characteristics } & \multirow[b]{2}{*}{ Categories } & \multicolumn{2}{|c|}{ Resected tooth status } & \multirow[b]{2}{*}{ Test } & \multirow[b]{2}{*}{ Statistics } & \multirow[b]{2}{*}{ p-value } \\
\hline & & Missing $(\mathrm{n}=89)$ & Present $(\mathrm{n}=60)$ & & & \\
\hline Age (Mean \pm SD, year) & At tooth resection & $47.3 \pm 9.9$ & $47.3 \pm 12.2$ & $\mathrm{t}$ & -0.035 & NS \\
\hline \multirow[t]{2}{*}{ Gender } & Male & $52(58.4)$ & $30(50.0)$ & $\chi^{2}$ & 1.028 & NS \\
\hline & Female & $37(41.6)$ & $30(50.0)$ & & & \\
\hline \multirow[t]{2}{*}{ Monthly household income $(\mathrm{HK} \$)^{\mathrm{a}}$} & $<10000$ & $35(39.3)$ & $15(25.0)$ & $\chi^{2}$ & 3.350 & NS \\
\hline & $\geq 20000$ & $30(33.7)$ & $26(48.3)$ & & & \\
\hline \multirow[t]{3}{*}{ Educational level } & No/Primary & $24(27.0)$ & $14(23.3)$ & $\chi^{2}$ & 1.705 & NS \\
\hline & Secondary & $44(49.4)$ & $26(43.3)$ & & & \\
\hline & Post-secondary & $21(23.6)$ & $20(33.3)$ & & & \\
\hline Smoking & Non-smoker & $67(75.3)$ & $48(80.0)$ & $\chi^{2}$ & 0.453 & NS \\
\hline \multirow[t]{2}{*}{ Systemic disease } & No & $55(61.8)$ & $46(76.7)$ & $\chi^{2}$ & 3.628 & NS \\
\hline & Yes & $34(38.2)$ & $14(23.3)$ & & & \\
\hline \multicolumn{7}{|l|}{ Dietary habits } \\
\hline \multirow[t]{2}{*}{ Hard food consumption } & No & $48(53.9)$ & $34(56.7)$ & $\chi^{2}$ & 0.108 & NS \\
\hline & Yes & $41(46.1)$ & $26(43.3)$ & & & \\
\hline \multirow[t]{2}{*}{ Snacking } & No & $54(60.7)$ & $33(55.0)$ & $\chi^{2}$ & 0.475 & NS \\
\hline & Yes & $35(39.3)$ & $27(45.0)$ & & & \\
\hline Daily soft drink consumption & No & $72(80.9)$ & $45(75.0)$ & $\chi^{2}$ & 0.739 & NS \\
\hline
\end{tabular}


$\begin{array}{lll}\text { Yes } & 17(19.1) & 15(25.0)\end{array}$

Oral Hygiene habits

Tooth brushing habit

$\leq 1$ time daily

$\geq 2$ times daily

No

$76(85.4)$

$13(14.6)$

$20(22.5)$

Yes

$69(77.5)$

$50(83.3)$

$10(16.7)$

Interdental brushing

No
Yes: private
Yes: hospital

$45(50.6)$

$50(83.3)$

Regular dental check-up

$9(10.1)$

$17(28.3)$

$6(10.0)$

$35(39.3)$

37 (61.7)

Results are Number (\%) unless otherwise indicated; NS = not significant.

${ }^{\mathrm{a}} \mathrm{HK} \$ 7.8=\mathrm{US} \$ 1$ (and pegged at that exchange rate) 
Table 2. Status of first and second molars in study participants

\begin{tabular}{|c|c|c|c|c|c|c|}
\hline & \multirow{3}{*}{$\begin{array}{l}\text { Baseline } \\
(\mathrm{n}=149)\end{array}$} & \multicolumn{4}{|c|}{ At recall ${ }^{\mathrm{a}}$} & \multirow[b]{3}{*}{ p-value } \\
\hline & & \multicolumn{2}{|c|}{ No SPC $(n=62)$} & \multicolumn{2}{|c|}{ With $\operatorname{SPC}^{\mathrm{b}}(\mathrm{n}=87)$} & \\
\hline & & Extracted & Standing & Extracted & Standing & \\
\hline Subject tooth & 149 & 45 & 17 & 44 & 43 & 0.011 \\
\hline $\begin{array}{l}\text { Other first/second } \\
\text { molars }\end{array}$ & 782 & 65 & 274 & 53 & 390 & 0.007 \\
\hline Total & 931 & 110 & 291 & 97 & 433 & \\
\hline
\end{tabular}

overall $\mathrm{p}<0.001$, Chi-square test

${ }^{b}$ including SPC at dental hospital and private dental practises

${ }^{\mathrm{c}}$ Chi-square test 
Table3.Dental status of study participants

\begin{tabular}{|c|c|c|c|c|c|c|}
\hline \multirow[b]{2}{*}{ Characteristics } & \multirow[b]{2}{*}{ Categories } & \multicolumn{2}{|c|}{ Resected tooth status } & \multirow[b]{2}{*}{ Test } & \multirow[b]{2}{*}{ Statistics } & \multirow[b]{2}{*}{$\mathrm{p}$-value } \\
\hline & & Missing $(\mathrm{n}=89)$ & Present $(n=60)$ & & & \\
\hline \multicolumn{7}{|l|}{$\begin{array}{l}\text { Pre-resective therapy records } \\
\text { Clinical data }\end{array}$} \\
\hline Tooth type & $\begin{array}{l}\text { Maxillary first molar } \\
\text { Maxillary second molar } \\
\text { Mandibular first molar } \\
\text { Mandibular second molar }\end{array}$ & $\begin{array}{c}49(55.1) \\
9(10.1) \\
23(25.8) \\
8(9.0)\end{array}$ & $\begin{aligned} 27 & (45.0) \\
4 & (6.7) \\
20 & (33.3) \\
9 & (15.0)\end{aligned}$ & $\chi^{2}$ & 3.030 & NS \\
\hline Tooth mobility $^{\mathrm{a}}$ & $\begin{array}{l}\text { M0 } \\
\text { MI } \\
\text { MII or above }\end{array}$ & $\begin{array}{l}26(29.2) \\
45(50.6) \\
18(20.2)\end{array}$ & $\begin{array}{c}28(46.7) \\
26(43.3) \\
6(10.0)\end{array}$ & $\chi^{2}$ & 5.731 & NS \\
\hline \multicolumn{7}{|l|}{$\begin{array}{l}\text { Radiographic data } \\
\text { Root morphology }\end{array}$} \\
\hline Trunk length & $\begin{array}{l}\text { Cervical } 1 / 3 \\
\text { Cervical } 1 / 2 \text { and } 2 / 3\end{array}$ & $\begin{array}{l}42(47.2) \\
47(52.8)\end{array}$ & $\begin{array}{l}30(50.0) \\
30(50.0)\end{array}$ & $\chi^{2}$ & 0.113 & NS \\
\hline Divergence angle $^{\mathrm{b}}$ & $\begin{array}{l}<15^{\circ} \\
\geq 15^{\circ}\end{array}$ & $\begin{array}{l}42(47.2) \\
47(52.8)\end{array}$ & $\begin{array}{l}34(56.7) \\
26(43.3)\end{array}$ & $\chi^{2}$ & 1.288 & NS \\
\hline \multicolumn{7}{|l|}{ Tooth support } \\
\hline Remaining bone level & $\begin{array}{l}\geq 75 \% \\
74-50 \% \\
<50 \%\end{array}$ & $\begin{array}{l}23(25.8) \\
38(42.7) \\
28(31.5)\end{array}$ & $\begin{array}{c}28(46.7) \\
30(50.0) \\
2(3.3)\end{array}$ & $\chi^{2}$ & 19.042 & $<0.001$ \\
\hline Crown-root ratio & $($ Mean $\pm \mathrm{SD}, \%)$ & $1.90 \pm 1.25$ & $1.25 \pm 0.53$ & $\mathrm{t}$ & 4.350 & $<0.001$ \\
\hline Endodontic treatment quality ${ }^{\mathrm{c}}$ & $\begin{array}{l}\text { Not good } \\
\text { Good }\end{array}$ & $\begin{array}{l}11(12.4) \\
78(87.6)\end{array}$ & $\begin{array}{l}10(16.7) \\
50(83.3)\end{array}$ & $\chi^{2}$ & 0.251 & NS \\
\hline Pre-treatment apical lesion size (mm) & $\begin{array}{l}\leq 2.0 \\
2.1-4.0\end{array}$ & $\begin{array}{l}63(70.8) \\
17(19.1)\end{array}$ & $\begin{array}{l}43(71.7) \\
15(25.0)\end{array}$ & $\chi^{2}$ & 2.815 & NS \\
\hline
\end{tabular}



$\geq 4.1$
$9(10.1)$
$2(3.3)$

Post-resective therapy records

Clinical data of resected tooth

Remaining root(s)

Type

Maxillary

Mandibular

Restorative status

Caries $^{\mathrm{f}}$

Antagonistic occluding units

Number of occluding pairs

Radiographic data

Quality of root resection ${ }^{\mathrm{e}}$

Presence of post and core

$\mathrm{MB}+\mathrm{DB}$
$\mathrm{DB}+\mathrm{P}$
$\mathrm{MB}+\mathrm{P}$
$\mathrm{P}$
$\mathrm{M}$
$\mathrm{D}$

Simple restoration

Coronal coverage

Bridge abutment/splinted

No

Yes

None

Removable denture

Fixed $^{\mathrm{d}}$

$($ Mean \pm SD)

Not good

Good

No

Yes

$32(36.0)$
$10(11.2)$
$13(14.6)$
$3(3.4)$
$17(19.1)$
$14(15.7)$

$71(79.8)$

$10(11.2)$

8 (9.0)

87(97.8)

2 (2.2)

5 (5.6)

7 (7.9)

77 (86.5)

$8.12 \pm 3.50$

14 (15.4)

75 (84.6)

87 (97.8)

2 (2.2)

$$
\begin{gathered}
14(23.3) \\
5(8.3) \\
8(13.3) \\
4(6.7) \\
13(21.7) \\
16(26.7)
\end{gathered}
$$

$$
30(50.0)
$$$$
16 \text { (26.7) }
$$$$
14 \text { (23.3) }
$$$$
55(91.7)
$$$$
5 \text { (8.3) }
$$

5 (8.3)

7 (11.7)

$48(80.0)$

$$
8.57 \pm 3.26
$$

$7(10.9)$

$53(89.1)$

$53(88.3)$

7 (11.7)
$-0.779$

NS

NS

$$
\chi^{2} \quad 14.572<0.001
$$$$
\chi^{2} \quad 2.965 \quad \text { NS }
$$$$
\chi^{2} \quad 1.126 \quad \text { NS }
$$ 


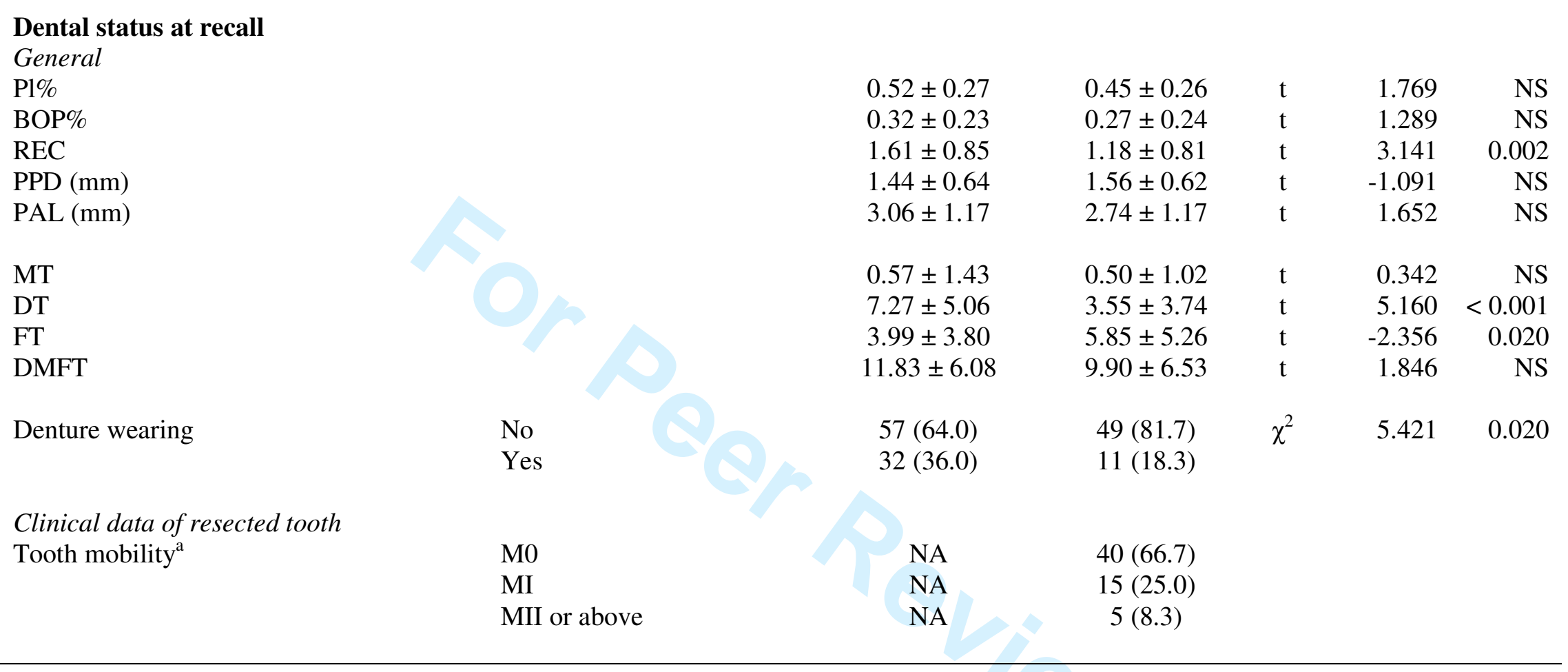

Results are Number (\%) unless otherwise indicated; $\mathrm{D}=$ distal; $\mathrm{DB}=$ distobuccal; $\mathrm{M}=$ mesial; $\mathrm{MB}=$ mesiobuccal; $\mathrm{NA}=$ not applicable; $\mathrm{NS}=$ not significant; $\mathrm{P}=$ palatal.

${ }^{a}$ Mobility-classified according to Miller's classification (Miller 1938).

${ }^{\mathrm{b}}$ Divergence for maxillary molars - only between mesiobuccal and distobuccal roots.

${ }^{\mathrm{c}}$ Intra-canal treatment quality - classified according to the Consensus Report of the European Society of Endodontology (2006).

${ }^{\mathrm{d}}$ Fixed units - tooth or tooth or implant borne crown or bridge unit.

${ }^{\mathrm{e}}$ Quality of root resection - classified according to Newell (1991).

${ }^{\mathrm{f}}$ Diagnosis aided radiographically. 
Table 4. Kaplan-Meier analysis on variables showing significant associations with period of resected tooth survival

\begin{tabular}{|c|c|c|c|c|c|c|}
\hline Characteristics & Categories (1-3) & $\mathrm{N}(\%)$ & $\begin{array}{c}\text { Median } \\
\text { survival } \\
\text { (months) }\end{array}$ & $\begin{array}{l}\text { 95\% Confidence } \\
\text { interval (months) }\end{array}$ & $\begin{array}{l}\text { Log-rank } \\
\text { Chi-square } \\
\text { p-value }\end{array}$ & $\begin{array}{c}\text { Between } \\
\text { categories } \\
\text { survival }\end{array}$ \\
\hline \multirow{3}{*}{ Remaining bone level } & $\geq 75 \%$ (1) & $51(34.2)$ & 156 & $94.4-217.6$ & $<0.001$ & $1>3$ \\
\hline & $74-50 \%(2)$ & $68(45.6)$ & 106 & $69.5-142.4$ & $<0.001$ & $2>3$ \\
\hline & $<50 \%$ & $30(20.1)$ & 25 & $2.6-47.4$ & & \\
\hline Pre-resection tooth & M0 (1) & $54(36.2)$ & 123 & $84.9-161.1$ & & \\
\hline \multirow[t]{2}{*}{ mobility $^{\mathrm{a}}$} & MI (2) & $71(47.7)$ & 62 & $51.3-72.7$ & 0.009 & $1>2$ \\
\hline & MII or above (3) & $24(16.1)$ & 39 & $0.0-81.3$ & 0.009 & $1>3$ \\
\hline \multirow[t]{3}{*}{ Restoration status } & Simple restoration (1) & $101(67.8)$ & 63 & $51.3-74.7$ & & \\
\hline & Coronal coverage (2) & $26(17.4)$ & 156 & $88.2-223.8$ & 0.006 & $1<2$ \\
\hline & Bridge abutment/splinted (3) & $22(14.8)$ & 227 & - & 0.006 & $1<3$ \\
\hline
\end{tabular}

Independent variables considered in Kaplan-Meier analysis but at the end not significant: age at root resection and at recall, gender, smoking, regular dental check-up (no/yes: private vs. hospital), tooth type, presence of post and core, and the following parameters at recall - $\mathrm{Pl} \%$, $\mathrm{BOP} \%$, PPD, REC, DT, FT, denture wearing. Crown-root ratio was not incorporated because of possible confounding with remaining bone level. ${ }^{a}$ Mobility- Classified according to Miller's classification (Miller 1938). 
Table 5. Multivariate Cox proportional hazards regression model for period of resected tooth survival

\begin{tabular}{|c|c|c|c|c|}
\hline Variable & Parameter estimate (B) & Standard Error (SE) & $p$-value & Hazard ratio $(95 \% \mathrm{CI})$ \\
\hline Age atresective treatment & 0.02 & 0.01 & 0.04 & $1.021(1.001-1.040)$ \\
\hline \multicolumn{5}{|l|}{ Bone height } \\
\hline$>75 \%$ & & & & 1 \\
\hline $74-50 \%$ & 0.49 & 0.28 & 0.08 & $1.626(0.943-2.807)$ \\
\hline$<50 \%$ & 1.51 & 0.31 & $<0.001$ & $4.515(2.460-8.287)$ \\
\hline \multicolumn{5}{|l|}{ Pre-resection toothmobility ${ }^{\mathrm{a}}$} \\
\hline M 0 & & & & 1 \\
\hline M I & 0.19 & 0.26 & 0.47 & $1.211(0.724-2.026)$ \\
\hline M II or above & 1.11 & 0.35 & 0.001 & $3.033(1.534-5.997)$ \\
\hline \multicolumn{5}{|l|}{ Restoration status } \\
\hline Simple restoration & & & & 1 \\
\hline Coronal coverage & -0.43 & 0.35 & 0.22 & $0.651(0.329-1.289)$ \\
\hline Bridge abutment/splinted & -1.34 & 0.42 & 0.002 & $0.263(0.115-0.603)$ \\
\hline
\end{tabular}

Result simplified from analysis of independent variables including age at recall, gender, smoking, regular dental check-up (no/yes: private vs. hospital), tooth type, presence of post and core, and the following parameters at recall - Pl\%, BOP\%, PPD, REC, DT, FT, and denture wearing which were found not significantly associated with period of resected tooth survival. Crown-root ratio was not incorporated because of possible confounding with remaining bone level.

${ }^{a}$ Mobility- Classified according to Miller's classification (Miller 1938) 

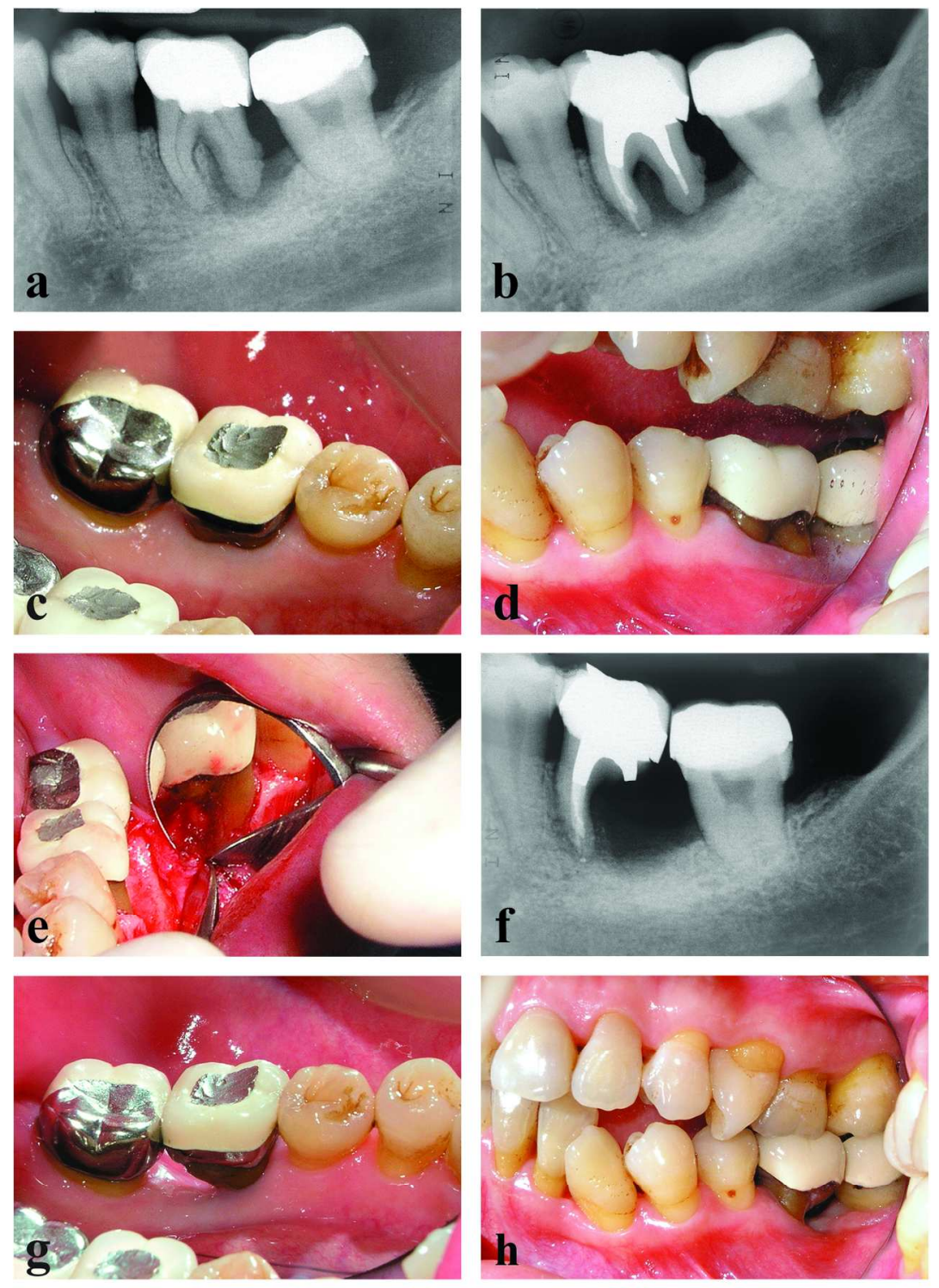

$140 \times 191 \mathrm{~mm}(300 \times 300$ DPI $)$ 